\title{
Comportamento dos Sistemas Sm-Nd e Rb-Sr da Seqüência Acamadada Máfico-Ultramáfica Ribeirão dos Motas (Arqueano), Cráton São Francisco Meridional: Evidências de Enriquecimento Mantélico e Fracionamento Isotópico
}

\author{
Maurício Antônio Carneiro' (mauricio@degeo.ufop.br), Wilson Teixeira², Irneu Mendes de Carvalho Júnior', \\ Márcio Martins Pimentel ${ }^{3}$, Arildo Henrique de Oliveira' \\ 'Departamento de Geologia - UFOP \\ Campus Morro do Cruzeiro, CEP 35400-000, Ouro Preto, MG, BRA \\ ${ }^{2}$ Departamento de Mineralogia e Geotectônica - Instituto de Geociências - USP, São Paulo, SP, BRA \\ ${ }^{3}$ Laboratório de Geocronologia - Instituto de Geociências - UnB, Brasília, DF, BRA
}

Palavras-chave: isótopos, $\mathrm{Sm}-\mathrm{Nd}, \mathrm{Sr}-\mathrm{Sr}$, rochas ultramáficas, Cráton São Francisco Meridional.

\section{RESUMO}

A Sequiência Acamadada Ribeirão dos Motas (SARM) aflora na porção meridional do Cráton São Francisco, na região centro-sul do Estado de Minas Gerais, Brasil. Essa seqüência é formada por rochas faneríticas metaultramáficas e metamáficas, variavelmente deformadas e metamorfisadas, exibindo, no entanto, acamamento magmático primário. Rochas porfiríticas com cristais idiomórficos de piroxênio e texturas heteradcumulática e adcumulática ocorrem esporadicamente. Dezoito amostras foram estudadas para obtenção da assinatura isotópica da SARM. Incluíram-se nesse conjunto, rochas com texturas primárias preservadas, rochas com paragênese metamórfica da facies anfibolito e, finalmente, rochas reequilibradas para facies xisto verde. Os resultados $\mathrm{Sm}-\mathrm{Nd}$ e Rb-Sr obtidos evidenciaram uma derivação mantélica, variavelmente enriquecida em isótopos de $\mathrm{Nd}$ e $\mathrm{Sr}$ e, ao mesmo tempo, a ocorrência de fracionamentos e distúrbios isotópicos. Do conjunto de dados $\mathrm{Sm}-\mathrm{Nd}$, sete amostras se alinharam numa isócrona com idade de $2,79 \pm 0,30 \mathrm{Ga}\left(\mathrm{MSWD}=1,2 \mathrm{e} \boldsymbol{\varepsilon}_{\mathrm{Ndt}}=+0,48\right)$, aqui interpretada como a melhor estimativa para a época de geração da SARM. Os fracionamentos e distúrbios isotópicos identificados decorrem, possivelmente, de uma das seguintes situações ou de suas combinações: a) o metamorfismo de alto grau (facies anfibolito) teria mobilizado heterogeneamente, em parte das rochas estudadas, o conteúdo dos elementos incompatíveis e, conseqüentemente, afetado as suas razões isotópicas $\mathrm{Sm} / \mathrm{Nd}$ originais; b) as modificações isotópicas teriam ocorrido, generalizadamente, durante o processo metamórfico de facies anfibolito superior, superimposto às rochas recém-cristalizadas da SARM; c) os sistemas isotópicos teriam sido afetados pela evolução da Zona de Cisalhamento Cláudio, que afetou tectonicamente a SARM. Essa estrutura poderia, inclusive, ter contribuído com fluidos adicionais para os processos metamórficos superimpostos às rochas da SARM, especialmente os de baixo grau, de modo a induzir o desequilíbrio isotópico.

Keywords: isotopes, Nd and Sr systematics, ultramafic rocks, São Francisco Craton.

\begin{abstract}
The Ribeirão dos Motas layered sequence (SARM) crops out in the southern part of the São Francisco Craton, Brazil. This sequence comprises phaneritic metaultramafic and metamafic rocks, which, although slightly deformed and metamorphosed, retain primary igneous layers. Porphyritic rocks with idiomorphic pyroxene crystals and heteradcumulate and adcumulate textures are also present. Eighteen isotopic analyses were performed in the SARM, comprising rocks with primary (relict) textures, as well as rocks in amphibolite facies and retro-metamorphosed to green-schist facies. Seven samples yield a Sm/Nd isochron age of $2.79 \pm 0.30 \mathrm{Ga}\left(\mathrm{MSWD}=1.2 \mathrm{e} \boldsymbol{\varepsilon}_{\mathrm{Ndt}}=+0.48\right)$, constraining the accretion time of the $\mathrm{SARM}$ rocks. The positive $\varepsilon_{\mathrm{Ndt}}$ value coupled with the $\mathrm{Rb} / \mathrm{Sr}$ evidence is consistent with mantle source relatively enriched in $\mathrm{Nd}$ and $\mathrm{Sr}$ isotopes. Nevertheless, some SARM samples display isotopic fractionation and disturbance, which can be ascribed to the following processes or their combinations: a) mobilization of the incompatible elements due to regional high grade metamorphism; b) isotopic changes during upper amphibolite facies overprint; c) isotopic resetting by low-grade fluids associated to the Cláudio Shear zone, which is located nearby the SARM.
\end{abstract}




\section{INTRODUÇÃO}

A presença de rochas máfico-ultramáficas na porção meridional do Cráton São Francisco (CSF), tem sido relatada de longa data (e.g. Barbosa, 1954). Essas ocorrências estão geneticamente, vinculadas às seqüências supracrustais arqueanas (e. g. Supergrupo Rio das Velhas) ou às sequiências supracrustais proterozóicas, como é o caso greenstone belt Itumirim - Tiradentes (Ávila, 2000; Machado Filho et al., 1983; Oliveira, 1999; Oliveira e Carneiro, 2001; Schorscher, 1979; Teixeira et al., 2000; Valença et al., 1998). Mais recentemente, um outro tipo de associação máficaultramáfica arqueana tem sido caracterizado nessa região. Trata-se de complexos ou sequiências acamadadas, como é o caso do Complexo Acamadado Morro das Almas (Barbosa et al., 1995) ou da Sequiência Acamadada Ribeirão dos Motas (SARM; Carvalho Júnior, 2001). Com o apoio de diferentes ferramentas interpretativas, o conhecimento geológico acerca da SARM vem sendo paulatinamente incrementado (Carneiro et al., 1996a, 1996b, 1997a, 1997b, 1997c, 1999; Carvalho Jr. et al., 1997, 1998a, 1998b; Carvalho Júnior, 2001; Carvalho Júnior e Carneiro, 1999; Correia da Costa, 1999; Fernandes, 2001). Neste estudo, apresentam-se os resultados isotópicos de $\mathrm{Nd}$ e $\mathrm{Sr}$ obtidos a partir de uma seleção de dezoito amostras da SARM. Para obtenção desse conjunto de dados, foram selecionadas amostras com características petrológicas contrastantes entre si, contemplando os seguintes agrupamentos:

a. litotipos com feições magmáticas preservadas e metamorfismo de facies anfibolito superior;

b. litotipos com feições magmáticas preservadas e metamorfismo de facies anfibolito superior, mas retrometamorfisados para facies xisto verde;

c. litotipos com mineralogia totalmente transformada para a facies xisto verde.

Usualmente, rochas com essas características petrogenéticas tendem a exibir um acentuado registro de mobilidade geoquímica, fato que poderia ser facilmente detectado no caso dos elementos maiores, menores ou traços. Todavia, o estudo geoquímico de Carvalho Júnior (2001) nas rochas da SARM, demonstrou que, independentemente do registro metamórfico ou deformacional de parte das amostras (exceto no caso de rochas muito transformadas na facies xisto verde), o seu padrão geoquímico geral era similar ao padrão das rochas com texturas e estruturas primárias preservadas. Assim, o objetivo principal desse estudo é o exame do comportamento dos sistemas isotópicos $\mathrm{Nd}$ e $\mathrm{Sr}$ nas rochas da SARM, frente aos processos metamórficos a elas superimpostos. Esta investigação, subsidiada pelo conhecimento geocronológico e isotópico das rochas da infra-estrutura do Cráton São Francisco Meridional (CSFM), permite caracterizar a assinatura petrogenética desse magmatismo máfico-ultramáfico.

\section{CONTEXTO GEOLÓGICO}

A SARM aflora na porção meridional do CSF, na região centro-sul do Estado de Minas Gerais (Figura 1).

Essa região é formada por um substrato siálico arqueano policíclico que hospeda várias seqüências supracrustais, além de rochas intrusivas e extrusivas ultramáficas, máficas e félsicas, geradas do Neoarqueano ao Neoproterozóico, circundado por cinturões móveis do Neoproterozóico (Carneiro et al., 1998a, 1998b; Chaves, 2001; Teixeira et al., 1996, 1998, 2000). Trabalhos de detalhe, realizados no âmbito do substrato siálico arqueano (e. g. Machado Filho et al., 1983; Teixeira et al., 1998, 2000) têm revelado uma vasta gama de litotipos, aqui agrupados no Complexo Metamórfico Campo Belo (CMCB), cuja história evolutiva remonta ao Mesoarqueano (e. g. Campos et al., 2003; Carneiro et al., 1996a, 1996b, 1997a, 1997b, 1997c; Carvalho Júnior, 2001; Carvalho Júnior et al., 1997; Corrêa da Costa, 1999; Fernandes, 2001; Oliveira, 1999; Oliveira e Carneiro, 2001; Oliveira, 2004; Teixeira et al., 1996, 1998, 2000). As rochas do CMCB são predominantemente metamórficas, de composição félsica, máfica e ultramáfica, correspondendo, respectivamente, a gnaisses de alto grau (facies granulito a anfibolito superior), granitóides (gnaissificados ou não), gabros (por vezes anfibolitizados) e metaperidotitos, metapiroxenitos e metahornblenditos acamadados (e. g. SARM). Na última década, os avanços alcançados no conhecimento geocronológico e isotópico do CMCB permitiram reconhecer vários episódios de sua evolução crustal, conforme abaixo sintetizado:

1. geração de protólitos do CMCB há cerca de $3,2 \mathrm{Ga}$ (Teixeira et al., 1998). Essa concepção é compatível com evidências isotópicas de $\mathrm{Pb}$ em zircões detríticos em rochas do greenstone belt Rio das Velhas no Quadrilátero Ferrífero (Machado et al., 1996).

2. evento acrescionário há cerca de 3,0 Ga com base em dados U-Pb SHRIMP e idades modelo $\mathrm{T}_{\mathrm{DM}}$ (entre 3,0 $2,9 \mathrm{Ga}$ ). Esse evento foi seguido de migmatização regional, datada entre 2,86-2,84 Ga (Teixeira et al., 2000) e plutonismo tardio, causando espessamento crustal.

3. geração de intrusões máfico-ultramáficas (e.g. SARM) e diques básico-noríticos (Carneiro et al., 1997a, 1997b, 1997c; Pinese, 1997), datados em 2,75 e 2,66 Ga, respectivamente. Esse magmatismo possui vínculo genético com episódios de extensão crustal, no âmbito do CMCB. Essa fase evolutiva desenvolveu-se em época contemporânea ao Evento Tectonotermal Rio das Velhas $(2,78$ - 2,7 Ga - Machado e 


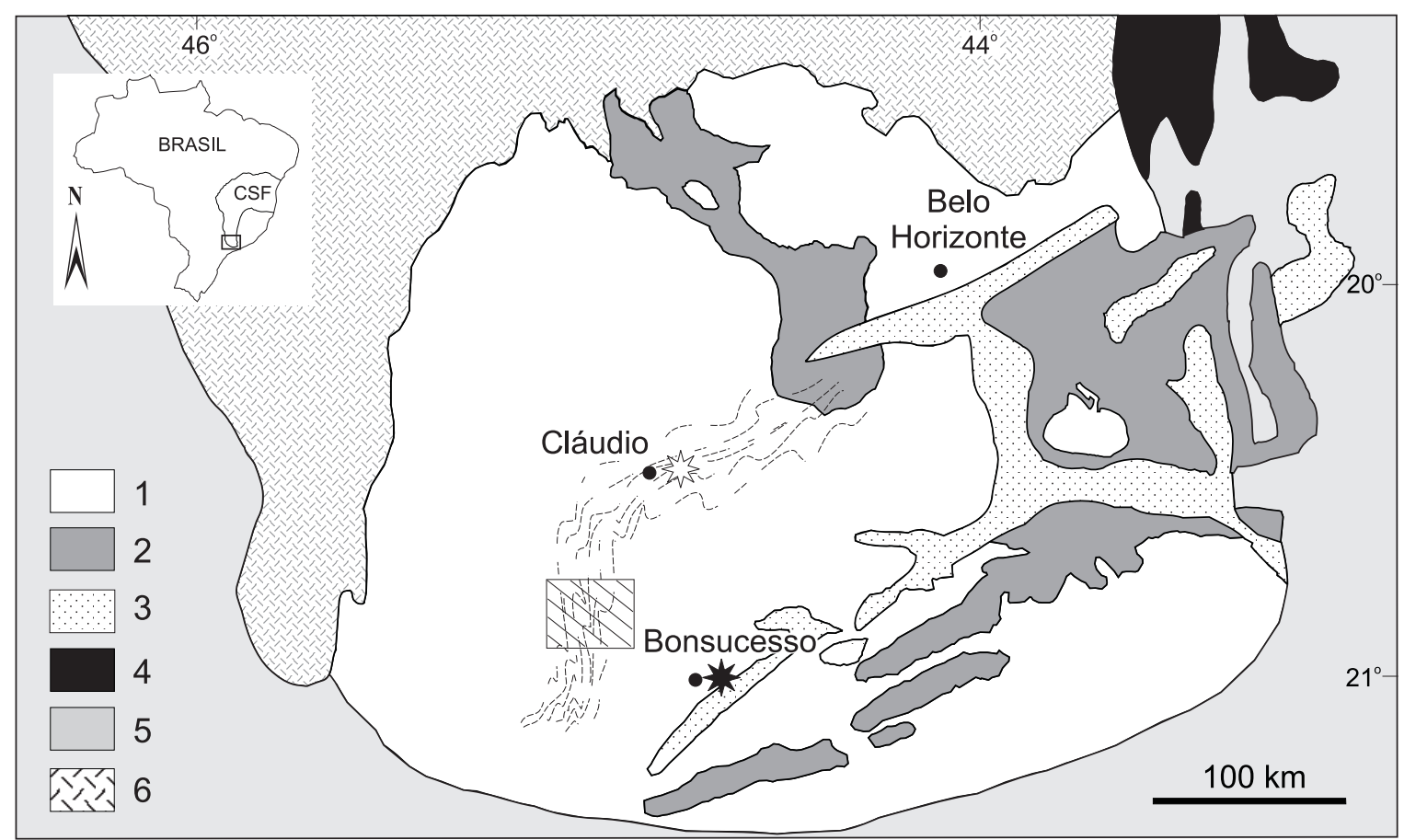

Figura 1. Mapa geológico simplificado da porção meridional do Cráton São Francisco, onde afloram as rochas da crosta siálica e as seqüências supracrustais arqueanas e proterozóicas. Na área hachurada localizamse os principais afloramentos da Seqüência Acamadada Ribeirão dos Motas (SARM - detalhes na Figura 2). Destaca-se também a Zona de Cisalhamento Cláudio (tracejado) e os locais de ocorrência da Seqüência Supracrustal Cláudio ( $\xi^{3}$ ) e Complexo Acamadado Morro das Almas ( $z_{k}$ ). Simbologia: 1. Crosta siálica. 2. Supergrupo Rio das Velhas. 3. Supergrupo Minas. 4. Supergrupo Espinhaço. 5. Cinturões móveis marginais. 6. Supergrupo São Francisco.

Carneiro, 1992) - configurando o cenário paleotectônico da margem continental no Neoarqueano.

4. episódio termo-tectônico regional afetando as rochas granitóides há cerca de 2,65 Ga, conforme refletido no reequilíbrio isotópico $\mathrm{Pb}-\mathrm{Pb}$ (Teixeira et al., 1996). Esse evento é contemporâneo com a anatexia e migmatização de determinadas partes do CMCB, identificados pelo sistema RbSr (Pinese, 1997), e causou re-homogeneização do sistema isotópico em rochas granulíticas da região de Lavras-Perdões, há cerca de 2,66 Ga (Teixeira et al., 1998). Adicionalmente, a leste do CMCB, datações U-Pb (zircão) em rochas granulíticas (Campos et al., 2003) indicaram idades entre 2,62 Ga (estimativa mínima da época do metamorfismo de alto grau) e 2,60 Ga (migmatização e granitogênese). Esse conjunto de dados isotópicos demonstra, portanto, que o Neoarqueano foi um período de retrabalhamento regional e de significativo re-equilíbrio isotópico das rochas da porção sul-ocidental do Cráton São Francisco Meridional.

\section{GEOLOGIA DA SARM}

\section{Modo de ocorrência e correlações gerais}

As rochas da SARM afloram em grandes blocos isolados e dispersos em meio a espesso manto de alteração de cor avermelhada escura. A disposição geográfica desses afloramentos no terreno determina um corpo irregular e segmentado. Esses segmentos se alinham, preferencialmente, na direção NE-SW (Figura 2), estando em contato (inferido) com as rochas do CMCB (Oliveira, 1999; Fernandes, 2001; Carvalho Júnior, 2001).

Outra característica marcante das rochas da SARM é uma forte estruturação interna, interpretada como acamamento magmático primário (Figura 3).

Embora acompanhado de uma foliação milonítica planoparalela, esse acamamento é indicativo dos processos 


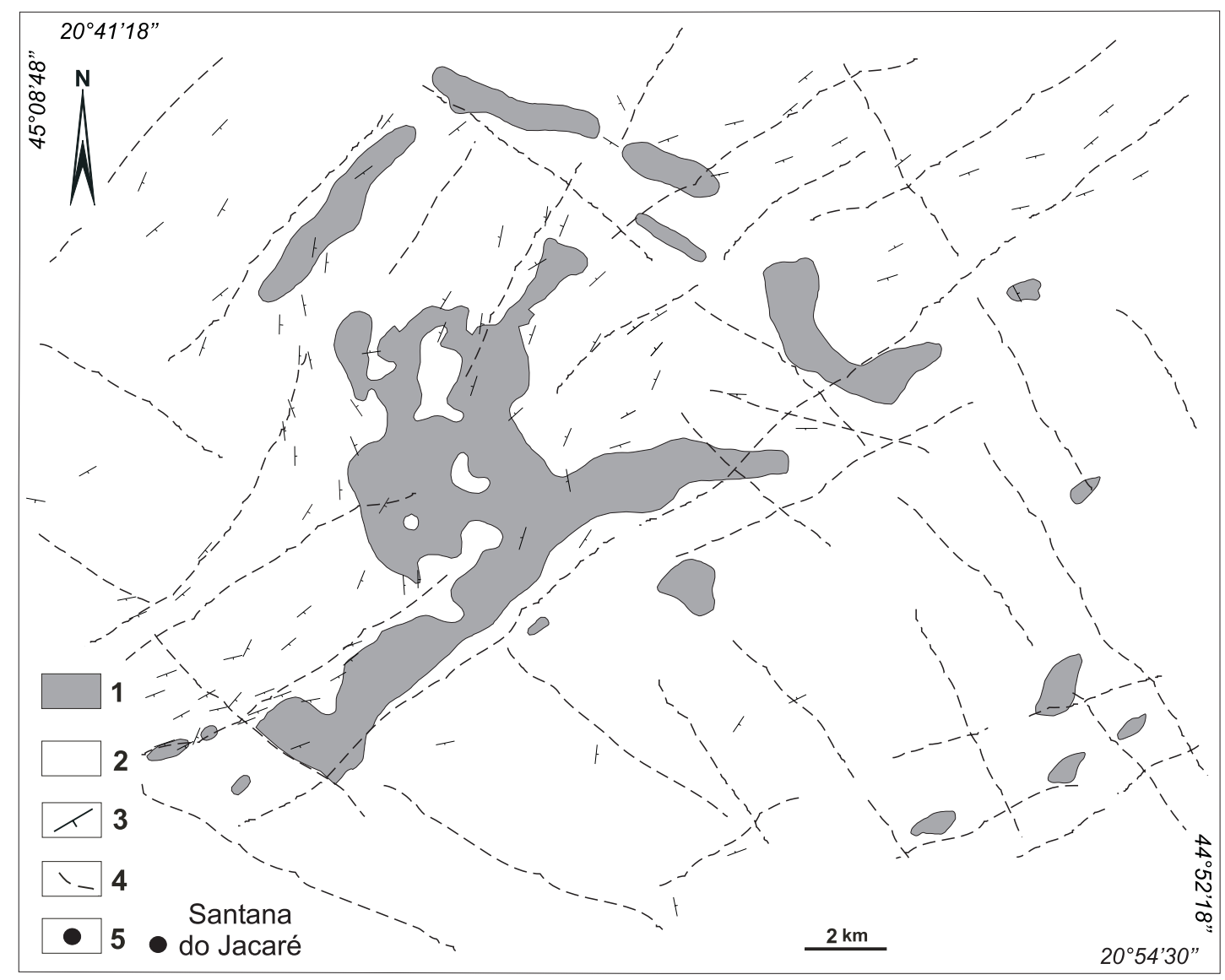

Figura 2. Mapa geológico simplificado do segmento crustal indicado na Figura 1, onde se destaca o corpo principal da Seqüência Acamadada Ribeirão dos Motas (SARM) e as demais ocorrências espalhadas pela área em questão, nos domínios do Complexo Metamórfico Campo Belo (CMCB). O corpo principal da SARM está envolvido pelas linhas de fluxo deformacional da Zona de Cisalhamento Cláudio que se prolonga para NE e passa pela cidade homônima (Figura 1). Simbologia: 1. SARM. 2. CMCB. 3. Foliação e sentido do mergulho. 4. Lineamento estrutural. 5. Cidade.

ígneos de acumulação magmática responsáveis pela formação das rochas dessa sequiência. De maneira geral, esse acamamento apresenta-se horizontalizado, subhorizontalizado, ou, até mesmo, subverticalizado. Indícios de deformação podem ser observados, tais como rotação desse acamamento magmático, dobras em chevron e padrões diversos de foliação. Nos planos de foliação ocorre fraturamento de ortopiroxênios mostrando que uma das fases do regime deformacional ocorreu próximo ao limite dúctil-rúptil. Esta foliação é caracterizada pela orientação de piroxênios (pequenos ribbons fraturados) e anfibólios em meio a porções de serpentina, subparalela ao bandamento composicional. No entanto, esporadicamente, são encontradas rochas ultramáficas porfiríticas isentas de deformação, contendo cristais idiomórficos de piroxênio. Nesses locais, também, as rochas exibem texturas cumuláticas do tipo heteradcumulática e adcumulática.
Acamamentos magmáticos ocorrem também nos metaultramafitos do Complexo Morro das Almas (Barbosa et al., 1995) e da Seqüência Supracrustal Cláudio (Oliveira, 1999; Oliveira e Carneiro, 2001), ambas as situações situadas no contexto geológico do CSFM (Figura 1). O Complexo Morro das Almas, que aflora na Serra de Bom Sucesso, é constituído de rochas ultramáficas metamorfisadas e deformadas, com feições primárias reliquiares, que indicam uma gênese relacionada a processos de acumulação magmática (e. g. alternância de termos compostos por olivina e piroxênio e termos mais ricos em piroxênio). Sobre esses ultramafitos ocorrem camadas de quartzito, xistos e formações ferríferas bandadas, relacionadas ao Supergrupo Minas. Essa situação geológica encontra similaridade com aquela da Sequiência Supracrustal Cláudio. Sua unidade basal é formada por rochas ultramáficas acamadadas (metaperidotitos 


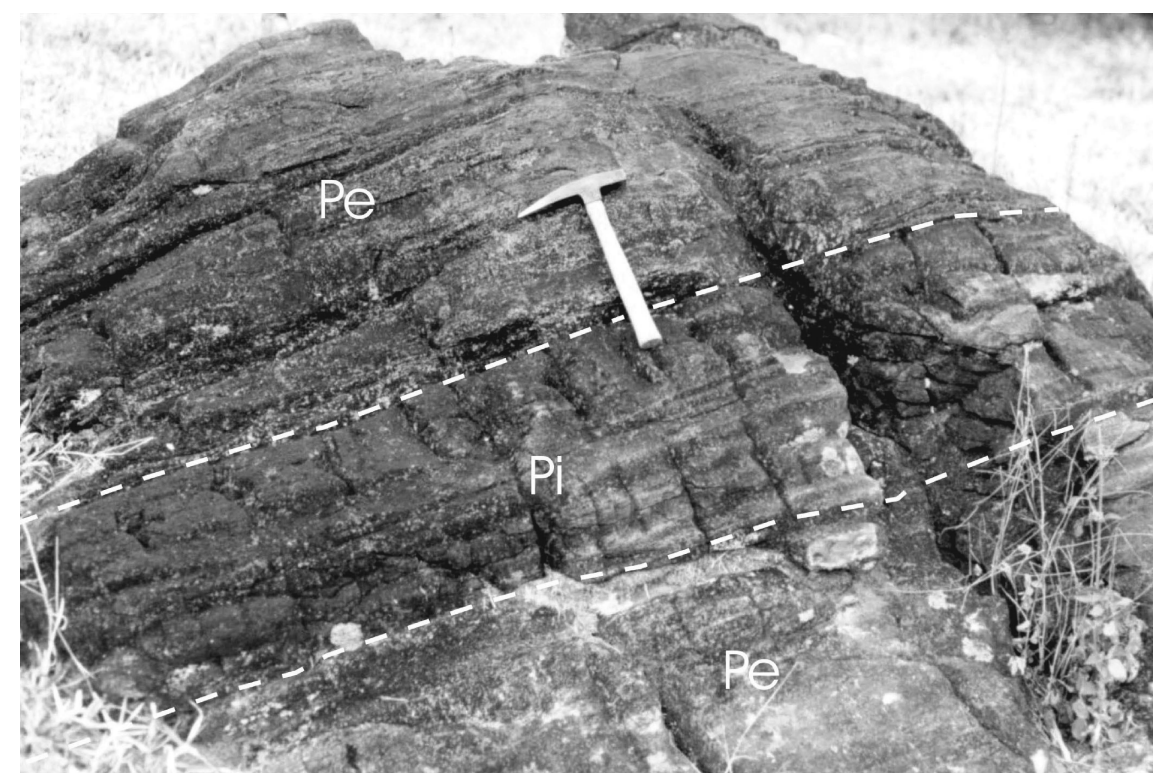

Figura 3. Afloramento típico da SARM mostrando a intercalação das camadas de metaperidotito $(\mathrm{Pe})$ e metapiroxenito $(\mathrm{Pi})$, interpretadas como acamamento magmático.

e metahornblenditos), com texturas provenientes de acumulação magmática e, para o topo da sequiência, ocorrem xistos, quartzitos e formação ferrífera bandada. Tectonicamente, a Seqüência Supracrustal Cláudio está posicionada ao longo da Zona de Cisalhamento Cláudio (Oliveira e Carneiro, 2001), que se prolonga para sudoeste (Figura 1), alcançando a área de ocorrência das rochas da SARM, nelas imprimindo foliação milonítica de caráter destral.

\section{Petrografia}

Petrograficamente, a SARM é formada por rochas faneríticas ultramáficas (metaperidotitos, metapiroxenitos e metahornblenditos) e máficas (metagabros, metagabronoritos e metanoritos) variavelmente metamorfisadas. Nos metaultramafitos são encontradas rochas do tipo olivina cumulatos (dunitos), tendendo a peridotitos harzburgíticos pelo aumento do conteúdo de ortopiroxênio (intercumulus). Nos casos onde se observam cristais bem formados de piroxênio (a olho nu, inclusive) esses litotipos podem ser classificados como piroxênio cumulatos. Contudo, a presença de abundante hornblenda, bem como a recristalização e transformação de parte da mineralogia desses metaultramafitos, dificultam a sua classificação segundo os critérios de acumulação magmática, descritos por Wager e Brown (1967). Além disso, se toda mineralogia fosse oriunda de recristalização ou transformação metassomática sob altas pressões, as rochas, nesse caso, poderiam ser classificadas como olivina enstatita fels, enstatita fels etc. (Bucher e Frey, 1994).

De maneira geral, os metaultramafitos da SARM são compostos por olivina, hornblenda magnesiana, enstatita e clinoenstatita, espinélio verde, clinocloro, serpentina, talco (raros casos) e opacos (alteração marginal do espinélio e produto da serpentinização da olivina e pirita). A olivina constitui a matriz nos leitos metaperidotíticos ou ocorre inclusa no ortopiroxênio (Figura 4).

Nesse caso, exibe-se, raramente, euédrica, mostrando, predominantemente, contatos abaulados. Apresenta pseudomorfose para serpentina verde clara, mineral que também ocorre nas fraturas de piroxênios (Figura 4). A clinoenstatita é rara. A enstatita, mais abundante, é incolor e encontra-se comumente associada a hornblenda que aparece como inclusões ou como substituição marginal dos piroxênios, não podendo ser descartada a hipótese de que parte dessa hornblenda seja magmática, conforme descrito por Carvalho Júnior e Carneiro (1999). Os piroxênios podem estar transformados para talco, sinalizando o metamorfismo de baixo grau superimposto aos metaultramafitos da SARM. Os espinélios se concentram em meio aos cristais-fantasma de olivina (polígonos semi-regulares), sugerindo que os primeiros são uma fase cúmulos (Figura 5).

Podem ocupar, também, os interstícios entre os cristais de olivina na matriz. Quando incluso no ortopiroxênio, o espinélio exibe seções retangulares e hexagonais, orientan- 


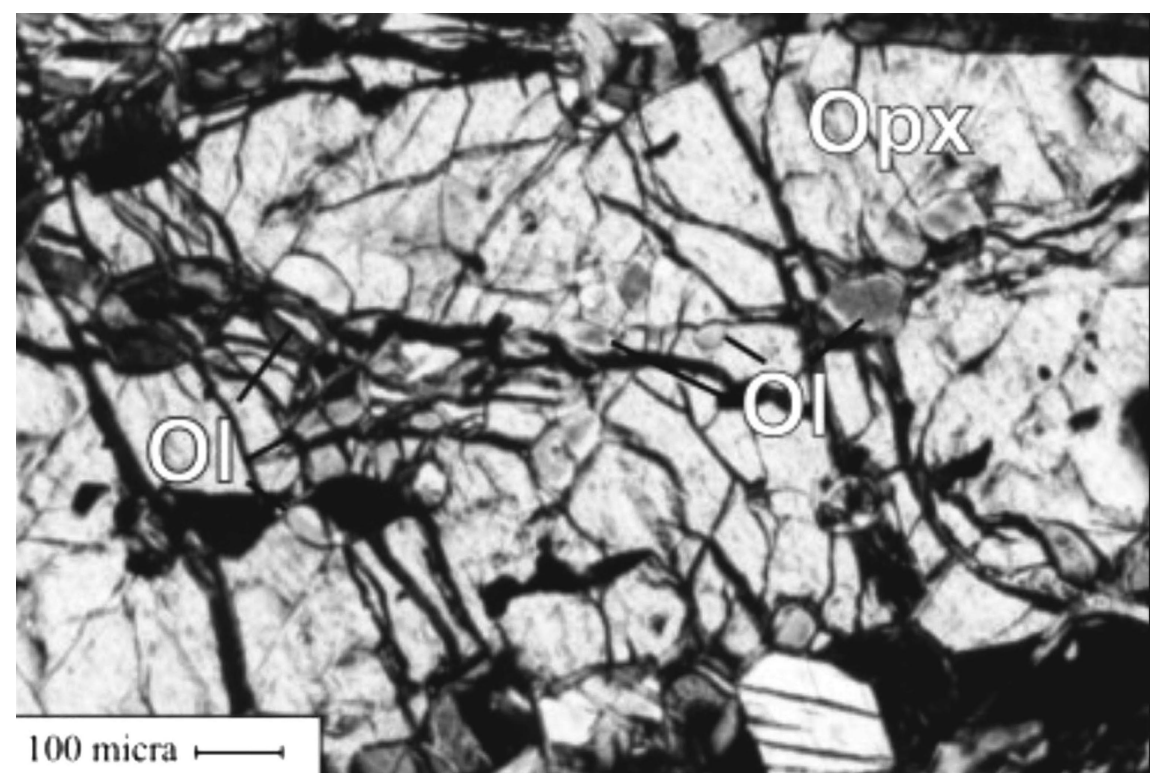

Figura 4. Fotomicrografia, em polarizadores cruzados (objetiva 10x) mostrando um oikocristal de ortopiroxênio (Opx), exibindo inclusões de olivina (Ol) com contatos abaulados, em rochas da SARM.

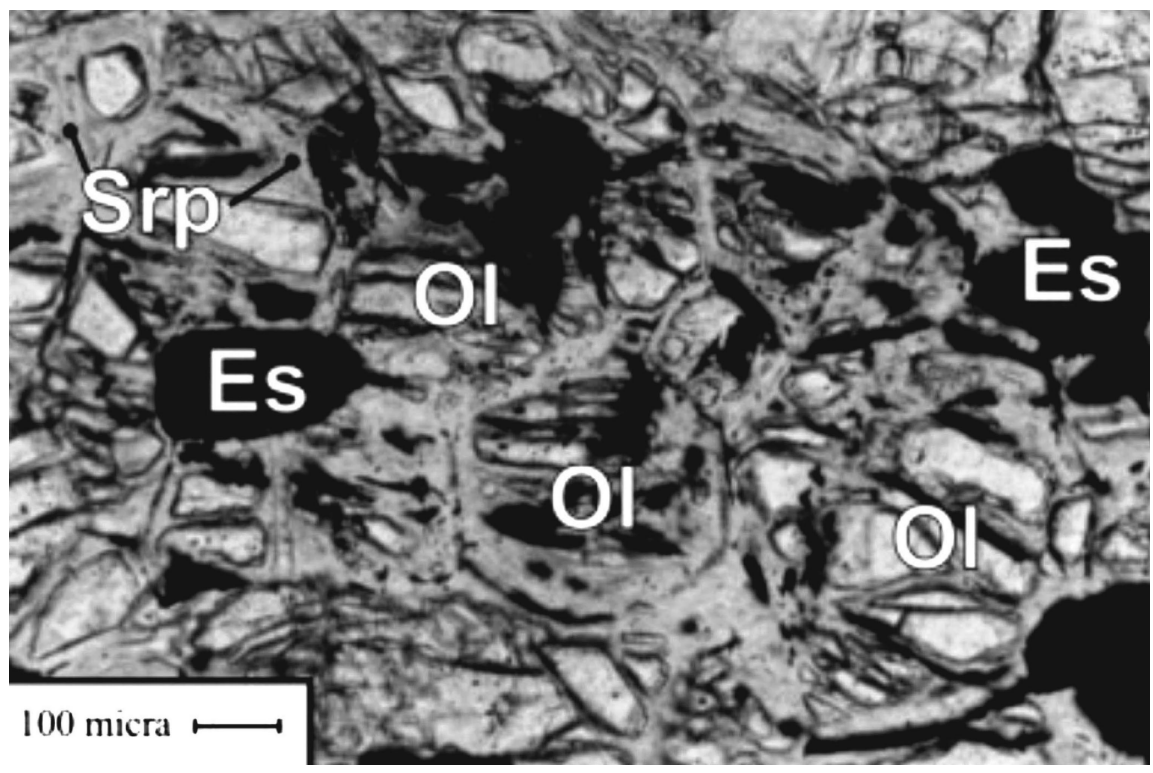

Figura 5. Fotomicrografia, em polarizadores descruzados (objetiva 10x) mostrando cristais de espinélio (Es) e cristais fantasmas de olivina (OI) adcumulática, serpentinizados (Srp), com resíduo opaco marginal, oriundo dessa serpentinização nas rochas da SARM. 
do-se segundo planos de clivagem ou partição desse mineral. O desenvolvimento de bordas opacas em torno do espinélio é um fato observado com freqüência, refletindo as condições metamórficas (facies xisto verde) em que se encontra reequilibrado esse mineral (Paktunç, 1984). Finalmente, o clinocloro associa-se ao espinélio, numa reação de consumo parcial desse último.

No caso dos metamafitos da SARM, a classificação de plagioclásio cumulato pode ser utilizada em algumas situações.

Também é observada nessas rochas a textura mesocumulática, quando ocorre um equilíbrio entre o piroxênio e o plagioclásio cumuláticos. Alguns desses metamafitos, onde o anfibólio secundário cresce com nítidas franjas sobre o clinopiroxênio, podem ser denominados de anfibolitos (s.s.). Em casos onde o metamorfismo atuou mais intensamente é comum as rochas estarem anfibolitizadas, exibindo uma textura granonematoblástica. Macroscopicamente, os metamafitos são anisotrópicos, mesocráticos a melanocráticos, mostrando coloração acinzentada escura a negra. São rochas essencialmente compostas por plagioclásio, enstatita, augita e hornblenda, em proporções variadas, apatita, minerais opacos e zircão. $\mathrm{O}$ plagioclásio apresenta maclas da albita e periclina e, em alguns casos, está quase completamente alterado para uma massa escurecida de saussurita. A enstatita apresenta-se fraturada e exibe alteração para anfibólio fibroso e talco. A augita exibe lamelas de exsolução de ortopiroxênio e bordas transformadas para hornblenda. A hornblenda aparece também como cristais subédricos a anédricos. A apatita (traços) ocorre como inclusões no plagioclásio e na hornblenda que também hospeda o zircão. Os opacos estão quase sempre associados ao piroxênio e ao anfibólio, exibindo cristais subédricos, por vezes dendríticos.

\section{Metamorfismo}

A principal paragênese dos metaultramafitos da SARM é representada por enstatita \pm olivina \pm hornblenda \pm clinoenstatita \pm espinélio. No caso de metamorfismo progressivo de rochas ultramáficas (e. g. Bucher e Frey, 1994; Evans e Frost, 1975; Paktunç, 1984) a paragênese usual seria: ortopiroxênio \pm olivina \pm tremolita \pm espinélio verde. No entanto, de acordo com Carvalho Júnior (2001) as análises por microssonda eletrônica, nos metaultramafitos e metamafitos da SARM, revelaram que todos os anfibólios, inclusive aqueles dos metamafitos, são hornblendas. Assim, ao invés de um metamorfismo progressivo, a paragênese magmática original (ortopiroxênio \pm olivina \pm clinopiroxênio) teria sido rapidamente re-equilibrada em condições metamórficas da facies anfibolito superior, sob pressões próximas a 5 Kbar. Nos casos em que fluidos hidratados atuam em peridotitos, sob condições metamórficometassomáticas de alta pressão, se o espinélio for consumido parcialmente, a paragênese final será formada por espinélio, ortopiroxênio, olivina e anfibólio (Schneider e Eggler, 1986). A trama granoblástica da SARM (anfibólio \pm ortopiroxênio \pm olivina em equilíbrio com o espinélio), caracteriza, portanto, a atuação de um processo metamórfico de facies anfibolito superior nas rochas estudadas. Nas rochas destituídas de olivina, a paragênese metamórfica de facies anfibolito superior é representada por hornblenda magnesiana \pm ortopiroxênio \pm espinélio. Por ser estável na facies anfibolito (Evans, 1977), o clinocloro ocorre com o espinélio nessa paragênese. A composição desse espinélio é rica em $\mathrm{Al}_{2} \mathrm{O}_{3}$ em virtude do ortopiroxênio não ser capaz de reter muita alumina nessas condições metamórficas (Evans, 1977). Assim, o espinélio pode ser oriundo da recristalização de uma enstatita rica em alumínio em alta pressão e temperatura. Posteriormente, as rochas da SARM sofreram retrometamorfismo para condições de facies xisto verde, evidenciado pela presença abundante de serpentina e, mais raramente, talco substituindo a olivina e os piroxênios.

\section{GEOQUÍMICA ISOTÓPICA}

\section{Metodologia}

A redução granulométrica das amostras, escolhidas para o estudo isotópico de $\mathrm{Nd}$ e $\mathrm{Sr}$, foi realizada no Laboratório de Preparação de Amostras para Geocronologia (LOPAG) do Departamento de Geologia da UFOP. Inicialmente, um britador de mandíbula (liga aço-manganês) foi utilizado para redução granulométrica das amostras. A seguir, o material foi pulverizado em moinho de carbeto de tungstênio, para atingir granulometria abaixo de 200 mesh. As análises isotópicas foram realizadas nos laboratórios dos Institutos de Geociências das universidades de Brasília - UnB (12 amostras) e de São Paulo (6 amostras). Os procedimentos analíticos relativos à abertura das amostras, ataque químico das alíquotas, soluções traçadoras empregadas, rotina de concentração de isótopos de $\mathrm{Nd}$, $\mathrm{Sm}$ e $\mathrm{Sr}$, e aquisição de dados espectrométricos seguiram as metodologias usuais dos laboratórios da UnB e CPGeo/USP, descritas respectivamente por Gioia e Pimentel (2000) e Sato et al. (1995). No caso do primeiro laboratório as razões isotópicas foram determinadas em espectrômetro de massa Finnigan MAT-262 multicoletor, com incertezas nas razões $\mathrm{Sm} / \mathrm{Nd}$ da ordem de $\pm 0,1 \%$. O valor médio do padrão internacional de $\mathrm{Nd}$ ( $\mathrm{La}$ Jolla; razão ${ }^{143} \mathrm{Nd} /{ }^{144} \mathrm{Nd}$ ) no laboratório da UnB é de 0,511843 (19). O branco para o procedimento químico foi de $<0,1 \mathrm{ng}$ para $\mathrm{Nd} \mathrm{e} \mathrm{0,2} \mathrm{ng} \mathrm{para} \mathrm{Sm} \mathrm{durante} \mathrm{o} \mathrm{período} \mathrm{das} \mathrm{análises.} \mathrm{No}$ CPGeo (USP), as razões isotópicas foram medidas em espectrômetro de massa multicoletor VG - 354, com erro 
estatístico das medidas ao nível $2 \sigma$. Os valores médios para a razão ${ }^{87} \mathrm{Sr} /{ }^{86} \mathrm{Sr}$ (NBS-987) e ${ }^{143} \mathrm{Nd} /{ }^{144} \mathrm{Nd}$ (La Jolla) foram respectivamente de 0,710253 (22) e 0,511857 (46), com desvios estatísticos ao nível $2 \sigma$ (parênteses). Portanto, os resultados obtidos para o padrão La Jolla em ambos os laboratórios são comparáveis dentro do erro. No CPGeo, as razões ${ }^{143} \mathrm{Nd} /{ }^{144} \mathrm{Nd} \mathrm{e}{ }^{147} \mathrm{Sm} /{ }^{144} \mathrm{Nd}$ tiveram erros máximos de $0,004 \%$ e $0,1 \%$ com nível de precisão de 2 e $1 \sigma$, respectivamente. Os valores máximos do branco durante o procedimento químico foram de $0,4 \mathrm{ng}(\mathrm{Nd})$ e $0,7 \mathrm{ng}(\mathrm{Sm})$, respectivamente. As idades modelo $\mathrm{T}_{\mathrm{DM}}$ foram calculadas com base nos seguintes parâmetros (DePaolo, 1988; DePaolo et al., 1991): $\mathrm{a}=0,25, \mathrm{~b}=-3 ; \mathrm{c}=8,5 \mathrm{e} \lambda=6,54 \times 10^{-12}$ anos $^{-1}$. Na normalização das razões ${ }^{143} \mathrm{Nd} /{ }^{144} \mathrm{Nd}$ assumiu-se o valor 0,7219 para a razão ${ }^{146} \mathrm{Nd} /{ }^{144} \mathrm{Nd}$, enquanto que para CHUR, as razões assumidas atuais para ${ }^{143} \mathrm{Nd} /{ }^{144} \mathrm{Nd}$ e ${ }^{147} \mathrm{Sm} /{ }^{144} \mathrm{Nd}$ foram 0,512638 e 0,1967 , respectivamente. Valores de $\varepsilon_{\mathrm{Nd}}$ foram calculados usando a equação simplificada $\boldsymbol{E}_{\mathrm{Nd}}(\mathrm{T})=\boldsymbol{\varepsilon}_{\mathrm{Nd}(0)}-$ $\mathrm{Q}_{\mathrm{Nd}} \mathrm{f}_{\mathrm{Sm} / \mathrm{Nd}} \mathrm{T}$, com base nos parâmetros CHUR acima e $\mathrm{Q}_{\mathrm{Nd}}=$ 25,09 . As razões ${ }^{87} \mathrm{Sr} /{ }^{86} \mathrm{Sr}$ foram normalizadas para o valor de 0,1194 (para ${ }^{86} \mathrm{Sr} /{ }^{88} \mathrm{Sr}$ ), enquanto que a modelagem (t) teve por base a equação ${ }^{87} \mathrm{Sr} /{ }^{86} \mathrm{Sr}{ }_{(\mathrm{t})}={ }^{87} \mathrm{Sr} /{ }^{86} \mathrm{Sr}-{ }^{87} \mathrm{Rb} /{ }^{86} \mathrm{Sr}\left(\mathrm{e}^{\lambda \mathrm{t}}-1\right)$, onde $\lambda=1,42 \times 10^{-11}$ anos $^{-1}$.

\section{RESULTADOS E DISCUSSÃO}

A Tabela 1 apresenta os dados analíticos das amostras da SARM, normalizados conforme os parâmetros acima. Especificamente com relação às análises $\mathrm{Rb} / \mathrm{Sr}$, a modelagem (t) para o cálculo das razões iniciais dependeu da disponibilidade de teores de $\mathrm{Sr}$ e $\mathrm{Rb}$, o que restringiu tal avaliação a 5 amostras (Tabela 1) do conjunto selecionado para os estudos.

Dezoito amostras foram analisadas pelo método $\mathrm{Sm}-\mathrm{Nd}$ e onze para obtenção de razões ${ }^{87} \mathrm{Sr} /{ }^{86} \mathrm{Sr}$. Estas últimas tiveram o objetivo de avaliar o efeito das transformações, uma vez que os isótopos de Sr não permitem nenhuma indicação geocronológica, face à reconhecida mobilidade do $\mathrm{Rb}(\mathrm{e}$ provavelmente $\mathrm{Sr}$ ) durante processos metamórficos. Duas análises Sm-Nd foram feitas em duplicata (JC027A; JC04H*) para atender ao controle qualitativo, tendo-se obtido valores concordantes dentro do erro analítico, porém com erros sensivelmente mais baixos (identificadas pela abreviatura "rep"). Essas repetições de análises serão as consideradas no estudo. Usualmente, apesar do sistema Sm-Nd preservar as características isotópicas originais do processo de diferenciação manto-crosta, durante processos de evolução da crosta continental, exemplos de fracionamento isotópico em decorrência de processos metamórficos, em especial aqueles de alto grau, têm sido relatados na literatura (e.g. Ben Othman et al., 1984; Burton e O'Nions, 1992; Tassinari et $a l ., 2003)$. Com base nessa consideração, o conjunto de dados isotópicos da SARM apresenta uma variação relativamente restrita das razões $\mathrm{Sm} / \mathrm{Nd}(0,181$ - 0,318), o que se deve essencialmente às múltiplas combinações de valores de $\mathrm{Nd}$ ou Sm de cada amostra. Contudo, muitas das razões $\mathrm{Sm} / \mathrm{Nd}$ obtidas são anormalmente baixas para rochas ultramáficas, o que se reflete nos teores incompatíveis observados (Nd e Sm muito elevados) em relação à composição original das rochas investigadas (e.g. Faure, 1986). Em função disso, optou-se pelo uso do parâmetro $\mathrm{f}_{\mathrm{Sm} / \mathrm{Nd}}$ como critério na seleção das amostras. $\mathrm{O}$ uso desse parâmetro revelou com melhor clareza a heterogeneidade anômala do conjunto, exemplificado pelos valores entre - 0,02 e - 0,44 , mesmo em se considerando a assinatura isotópica típica de partes máficas da crosta (e. g. Bennet e DePaolo, 1987). Portanto, fica patente o fracionamento isotópico de boa parte das amostras investigadas da SARM (i. e. comportamento químico móvel das terras raras leves), fenômeno esse, aqui assumido, como relacionado ao evento metamórfico de alto grau (e. g. Teixeira et al., 2000; Campos et al., 2003), datado em cerca de 2,6 Ga (ver item seção "contexto geológico"), que atuou no CSFM. Esse fracionamento do sistema Sm$\mathrm{Nd}$, por outro lado, está ilustrado isotopicamente pela dispersão das dezoito amostras no diagrama de correlação ${ }^{147} \mathrm{Sm} /{ }^{144} \mathrm{Nd} v{ }^{143} \mathrm{Nd} /{ }^{144} \mathrm{Nd}$, com indefinição de um trend principal, o que inviabiliza o cálculo de uma idade isocrônica para o conjunto (Figura 6A). Em adição, o fracionamento está ilustrado pela disparidade de idades modelo que, se calculadas, forneceriam valores irreais entre 3,7 e 1,4 Ga (Tabela 1).

Por outro lado, quatro amostras com $\mathrm{f}_{\mathrm{Sm} / \mathrm{Nd}}$ entre - $0,23 \mathrm{e}$ - 0,27 (intervalo típico para materiais acrescionados à crosta continental; Taylor e McLennan, 1992) possivelmente representam o sistema isotópico original da SARM, a saber: três amostras (JC27Arep, JC27C, JC313), com textura ígnea reliquiar e metamorfismo de facies anfibolito; uma amostra (JC471A) com textura ígnea preservada, facies anfibolito e retrometamorfismo para facies xisto verde (Tabela 1). A princípio, portanto, as demais amostras teriam possivelmente seus sistemas $\mathrm{Sm}-\mathrm{Nd}$ re-equilibrados. Utilizando por base as rochas sem retrometamorfismo para facies xisto verde, verifica-se que os valores recalculados de $\varepsilon_{\mathrm{Nd}(2,6 \mathrm{Ga})}$ variam significativamente entre positivos e negativos, o que é novamente incomum para o tipo de rochas em estudo. Do mesmo modo, a variação isotópica das razões iniciais ${ }^{87} \mathrm{Sr} /{ }^{86} \mathrm{Sr}_{(0)}$ (ver Tabela 1), embora não obedeça a uma tendência, em boa parte, é condizente com material crustal enriquecido na razão $\mathrm{Rb} / \mathrm{Sr}$. Isso, novamente, é incompatível com a natureza ultramáfica das rochas investigadas, o que reforça a hipótese de modificações do sistema isotópico original da SARM.

As quatro amostras citadas acima (representativas teoricamente do sistema isotópico original da SARM) apresen- 
Tabela 1. Resultados Sm-Nd (18 amostras, com duas repetições) e Sr-Sr (11 amostras) em rocha total da SARM. As análises marcadas com (*) foram obtidas no CPGeo/USP e aquelas marcadas com ( $\left.{ }^{* *}\right)$ no IG/UnB. Abreviações: Hb - hornblenda. Px - piroxênio. rep - repetição.

\begin{tabular}{|c|c|c|c|c|c|c|c|c|c|c|c|c|c|c|c|c|c|c|}
\hline Amostra & Rocha & $\begin{array}{l}\text { Coordenadas } \\
\text { geográficas } \\
\text { do ponto } \\
\text { amostrado }\end{array}$ & $\begin{array}{c}\text { Sm } \\
(\mathbf{p p m})\end{array}$ & $\begin{array}{c}\mathrm{Nd} \\
(\mathrm{ppm})\end{array}$ & ${ }^{147} \mathrm{Sm} /$ & erro & ${ }^{143} \mathrm{Nd} /$ & erro & $f_{S m / N d}$ & $\begin{array}{l}\mathrm{T}_{\mathrm{DM}} \\
(\mathrm{Ga})\end{array}$ & $\varepsilon_{(0)}$ & $\mathcal{E}_{(2,78 \mathrm{Ga})}$ & $\varepsilon_{(2,66 \mathrm{Ga})}$ & $\begin{array}{l}{ }^{87} \mathrm{Sr}^{86} \mathrm{Sr} \\
\text { (0) }\end{array}$ & $\begin{array}{l}{ }^{87} \mathrm{Sr} r^{86} \mathrm{Sr} \\
(\mathrm{T} 2,78 \mathrm{Ga})\end{array}$ & $\begin{array}{c}\mathcal{E}_{\mathrm{sr}} \\
(2,78 \mathrm{Ga})\end{array}$ & $\begin{array}{c}\mathcal{E}_{\mathrm{Sr}} \\
(2,66 \mathrm{Ga})\end{array}$ & $\begin{array}{l}\text { Características } \\
\text { da amostra }\end{array}$ \\
\hline$J^{\prime}$ C027C & Meta Hb. Piroxenito & $769937 ; 49318$ & 0,453 & 1,917 & 0,1429 & 0,0014 & 0,511608 & 0,000029 & $-0,27$ & 3,1 & $-20,09$ & $-1,01$ & $-1,84$ & 0,70352 & 0,69591 & $-75,70$ & $-72,97$ & Textura ígnea \\
\hline$J^{\prime}$ C027A* rep & Meta Hb. Piroxenito & $769937 ; 49318$ & 0,406 & 1,707 & 0,1440 & 0,0001 & 0,511698 & 0,000019 & $-0,27$ & 3,0 & $-18,34$ & 0,35 & $-0,46$ & - & - & - & - & reliquiar e \\
\hline JC027A1* & Hb. Piroxenito & $769937 ; 49318$ & 0,414 & 1,738 & 0,1440 & 0,0014 & 0,511700 & 0,000300 & $-0,27$ & 3,0 & $-18,30$ & 0,37 & $-0,43$ & - & - & - & - & metamorfismo de \\
\hline $\mathrm{JC} 073 \mathrm{C}^{*}$ & Meta Gabronorito & $769772 ; 49343$ & 4,254 & 14,978 & 0,1717 & 0,0006 & 0,512153 & 0,000034 & $-0,13$ & 3,4 & $-9,46$ & $-0,61$ & $-0,99$ & - & - & - & - & facies anfibolito \\
\hline $\mathrm{JC} 073 \mathrm{M}^{*}$ & Meta Gabronorito & $769772 ; 49343$ & 4,019 & 14,314 & 0,1698 & 0,0006 & 0,512180 & 0,000047 & $-0,14$ & 3,1 & $-8,93$ & 0,61 & 0,20 & - & - & - & - & \\
\hline$J C 108 A^{* *}$ & Anfibolito & $770368 ; 49294$ & 2,491 & 9,622 & 0,1565 & 0,0016 & 0,511630 & 0,000014 & $-0,20$ & - & $-19,66$ & $-5,43$ & $-6,04$ & 0,70941 & - & - & - & retrometamorfismo \\
\hline JC207A** & Hb. Piroxenito & $770955 ; 49765$ & 3,216 & 17,553 & 0,1108 & 0,0011 & 0,511587 & 0,000003 & $-0,44$ & - & $-20,50$ & 9,96 & 8,65 & - & - & - & - & para facies xisto \\
\hline JC313** & Meta Piroxenito & $770808 ; 49242$ & 0,944 & 3,750 & 0,1522 & 0,0015 & 0,511850 & 0,000011 & $-0,23$ & 3,0 & $-15,37$ & 0,40 & $-0,28$ & 0,72399 & 0,71039 & 130,86 & 137,30 & \\
\hline $\mathrm{JC} 026 \mathrm{C}^{*}$ & Meta Px. Peridotito & $769952 ; 49317$ & 0,275 & 0,880 & 0,1890 & 0,0007 & 0,512700 & 0,000500 & $-0,04$ & - & 1,21 & 3,94 & 3,83 & - & - & - & - & \\
\hline $\begin{array}{ll}\mathrm{JC} 057 A^{*} \\
\end{array}$ & Meta Px. Hb. Peridotito & $766584 ; 49054$ & 0,213 & 0,738 & 0,1745 & 0,0001 & 0,512678 & 0,000022 & $-0,11$ & - & 0,78 & 8,64 & 8,30 & - & - & - & - & Textura ígnea \\
\hline$J C 067^{\star \star}$ & Meta Hb. Peridotito & $769838 ; 49349$ & 0,372 & 1,323 & 0,1700 & 0,0017 & 0,512171 & 0,000024 & $-0,14$ & 3,1 & $-9,11$ & 0,35 & $-0,06$ & 0,71168 & 0,68042 & $-296,48$ & $-278,87$ & preservada, \\
\hline$J C 180 A^{* *}$ & Meta $\mathrm{Hb}$. Peridotito & $770139 ; 49423$ & 0,357 & 1,221 & 0,1768 & 0,0018 & 0,512186 & 0,000028 & $-0,10$ & - & $-8,82$ & $-1,76$ & $-2,07$ & 0,72183 & 0,70002 & $-17,07$ & $-5,45$ & metamorfismo de \\
\hline JC408** & Meta Piroxenito & $770853 ; 50039$ & 2,919 & 16,090 & 0,1097 & 0,0011 & 0,511368 & 0,000021 & $-0,44$ & - & $-24,77$ & 6,08 & 4,74 & 0,71806 & - & - & & facies anfibolito e \\
\hline$J C 471 A^{* *}$ & Px. Hb. Gabronorito & $769889 ; 49622$ & 1,447 & 5,891 & 0,1485 & 0,0015 & 0,511656 & 0,000012 & $-0,24$ & 3,3 & $-19,16$ & $-2,08$ & $-2,81$ & 0,71824 & 0,71618 & 213,39 & 212,58 & retrometamorfismo \\
\hline$J C 639 A^{* *}$ & Hb. Piroxenito & $768358 ; 50457$ & 4,155 & 15,325 & 0,1639 & 0,0016 & 0,512114 & 0,000034 & $-0,17$ & 2,9 & $-10,22$ & 1,39 & 0,89 & 0,70481 & - & - & & para facies xisto \\
\hline JC833** & Px. Hb. Peridotito & $768005 ; 50440$ & 0,131 & 0,409 & 0,1937 & 0,0019 & 0,512798 & 0,000086 & $-0,02$ & - & 3,12 & 4,19 & 4,15 & 0,70327 & - & - & - & verde (abundante \\
\hline $\mathrm{JC}-4 \mathrm{H}^{*}$ & Meta Piroxenito & $769971 ; 49300$ & 0,427 & 1,470 & 0,1757 & 0,0008 & 0,511970 & 0,000120 & $-0,11$ & - & $-13,03$ & $-5,57$ & $-5,89$ & - & - & - & - & serpentina) \\
\hline
\end{tabular}


tam parâmetros negativos de $\mathcal{E}_{\mathrm{Nd} 0}(-15,37$ a - 20,09) e são, portanto, passíveis de cálculo de idades $\mathrm{T}_{\mathrm{DM}}(3,0$ a 3,3 Ga; Tabela 1). Idades modelo (DM) dessa ordem são típicas das rochas do CMCB (e. g. 2,9-3,1Ga) e sinalizam importante evento acrescionário no CSFM (e. g. Teixeira et al., 1996). Por outro lado, as quatro idades $\mathrm{T}_{\mathrm{DM}}$ (ver acima) são comparáveis, dentro do erro inerente do método ( $200 \mathrm{Ma})$, às idades-modelo obtidas para as amostras JC73C, JC73M, JC67, JC639A (2,9-3,3 Ga; Tabela 1). Isso sugere que esses sistemas $\mathrm{Sm-Nd}$ podem também não ter sofrido fracionamento isotópico. Ao se assumir tal hipótese como válida, os valores de $\mathrm{f}_{\mathrm{Sm} / \mathrm{Nd}}$ nesses últimos casos (entre 0,13 e - 0,17; Tabela 1) refletiriam partes mais máficas da crosta, conforme descrito na literatura. Em suma, de acordo com esse raciocínio, a assinatura isotópica primária da SARM seria ilustrada, portanto, por essas oito amostras. Contudo, uma amostra desse conjunto (JC471A), quando tratado em diagrama de correlação isotópica, não se insere no alinhamento formado pelas demais amostras (ver adiante), de modo que não será aqui considerada como representativa das características originais da SARM. O conjunto formado pelas sete amostras consideradas exibe razões ${ }^{143} \mathrm{Nd} /{ }^{144} \mathrm{Nd}$ em dois intervalos restritos $(0,5116-0,5118 \mathrm{e}$ 0,5121 - 0,5122) e sua correlação com as respectivas razões ${ }^{147} \mathrm{Sm} /{ }^{144} \mathrm{Nd}(0,1429$ - 0,1522 e 0,1639 - 0,1717) constitui uma isócrona com idade de 2,79 $\pm 0,30$ Ga (MSWD = 1,2) e $\varepsilon_{\mathrm{Ndt}}=+0,48$ (Figura 6B). Trata-se de uma estimativa concre- ta para idade da geração da SARM, com base nas premissas da sistemática $\mathrm{Sm}-\mathrm{Nd}, \boldsymbol{\varepsilon}_{\mathrm{Ndt}}$ positivo, interpretação esta que se coaduna, inclusive, com o conhecimento atual da evolução crustal da parte meridional do Cráton do São Francisco.

Para testar a hipótese da existência de contaminação crustal, as sete amostras selecionadas foram representadas em diagrama de correlação $\mathcal{E}_{\mathrm{Nd}} v s{ }^{147} \mathrm{Sm} /{ }^{144} \mathrm{Nd}$, modelado para $\mathrm{t}=2,78 \mathrm{Ga}$ (Figura 7), idade do Evento Tectonotermal Rio das Velhas (Machado e Carneiro, 1992).

Nesse diagrama foram incluídas as assinaturas do $\mathrm{CMCB}$ $\left(\boldsymbol{E}_{\mathrm{Nd}(2,78 \mathrm{Ga})}\right.$ predominantemente negativos e ${ }^{147} \mathrm{Sm} /{ }^{144} \mathrm{Nd}$ entre $0,10-0,12)$, bem como os parâmetros DM e CHUR e, ainda, as amostras restantes da SARM (notar especialmente o posicionamento anômalo da amostra JC471A ( $c f$. dados na Tabela 1), reforçando a hipótese da presença de distúrbio isotópico). Observa-se que as sete amostras distribuemse num campo à esquerda dos componentes DM e CHUR $\left({ }^{147} \mathrm{Sm} /{ }^{144} \mathrm{Nd}<0,20\right)$. Esse comportamento sugere um enriquecimento mantélico (a partir de uma fonte originalmente empobrecida; valores de $\mathcal{E}_{\mathrm{Nd}(2,78 \mathrm{Ga})}$ entre os parâmetros DM e CHUR), e ainda, eventualmente, a presença de contaminação crustal $\left(\boldsymbol{E}_{\mathrm{Nd}(2,78 \mathrm{Ga})}=-1,01\right.$; amostra JC027C). Especificamente no caso da amostra JC600B $\left(\boldsymbol{E}_{\mathrm{Nd}(2,78 \mathrm{Ga})}=-0,26\right)$ sua assinatura parece refletir uma perturbação decorrente da transformação mineralógica intensa. Digno de nota também é a distribuição anômala das amostras restantes da SARM, incompatível, inclusive, com a evolução teórica do manto
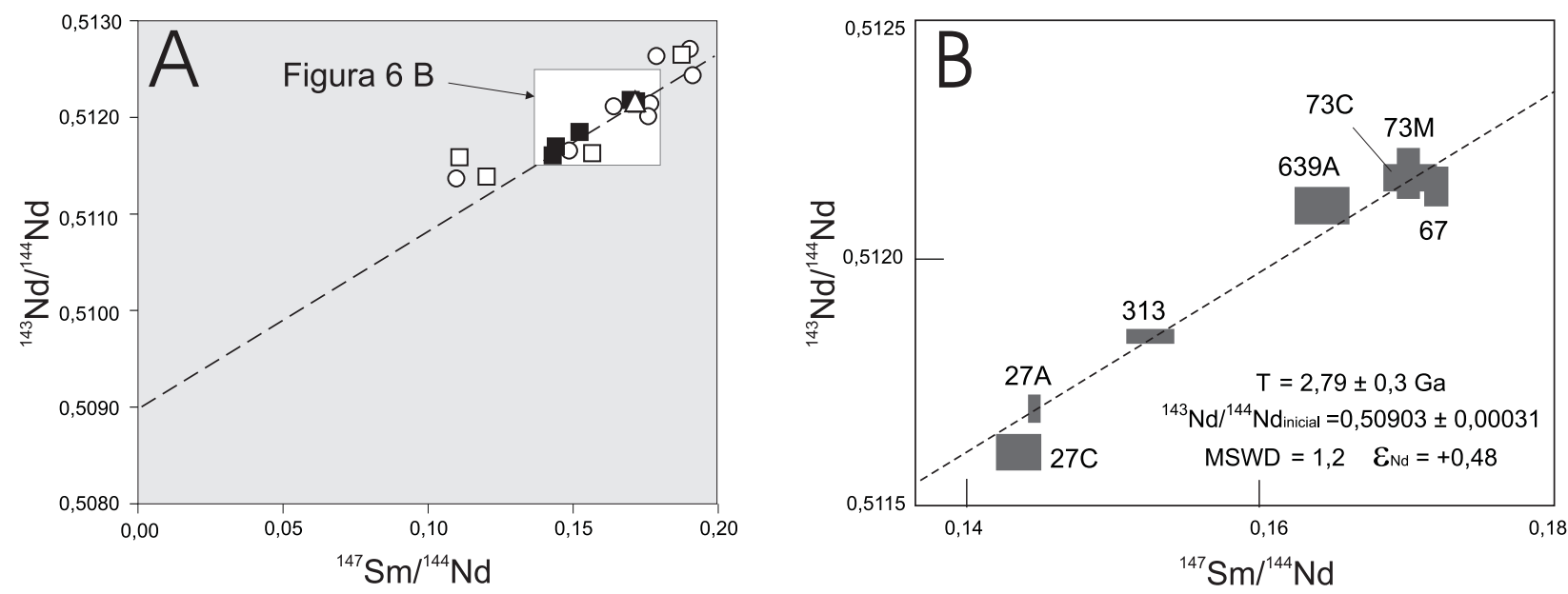

Figura 6. A - Diagrama de correlação ${ }^{147} \mathrm{Sm} /{ }^{144} \mathrm{Nd}$ vs ${ }^{143} \mathrm{Nd} /{ }^{144} \mathrm{Nd}$ onde a dispersão anômala de dados ilustra o fracionamento isotópico de parte dos sistemas (símbolos cheios representam as amostras preservadas isotopicamente cf. texto e Tabela 1). B - Detalhe ampliado de parte do diagrama A onde as sete amostras, com sistema isotópico preservado, definem um alinhamento com idade de 2,79 Ga, interpretada como época da geração da SARM. Simbologia: Quadrados - amostras sem retrometamorfismo para a facies xisto verde. Círculos - amostras com retrometamorfismo para a facies xisto verde. Triângulo - amostra totalmente transformada para a facies xisto verde. 
empobrecido no tempo (e. g. valores de $\left.\mathcal{E}_{\mathrm{Nd}(2,78 \mathrm{Ga})}>+6\right)$, o que demonstra novamente a existência de fracionamento isotópico. De outra parte, a distribuição de alguns valores de $\varepsilon_{\mathrm{Nd}(2,78 \mathrm{Ga})}$ negativos desse grupo de amostras (e. $g$. JC180A) nas proximidades do campo isotópico do CMCB admite, teoricamente, a possibilidade de interação com crosta continental.

Em suma, tendo em conta a estimativa de idade da SARM, os valores calculados de $\mathcal{E}_{\mathrm{Nd}(2,78 \mathrm{Ga})}$ para as sete amostras mais preservadas isotopicamente $\left(\boldsymbol{\varepsilon}_{\mathrm{Nd}(2,78 \mathrm{Ga})}=+0,35 ;+0,35\right.$; $+0,40 ;+0,61 ;+1,39 ;-0,61 ;-1,01)$ e ainda a grande variação das razões ${ }^{87} \mathrm{Sr} /{ }^{86} \mathrm{Sr}_{(2,78 \mathrm{Ga})}$ (e. g. entre o valor anômalo de 0,6804 a 0,7162), a assinatura resultante é compatível com uma fonte mantélica metassomatisada a partir da qual os precursores magmáticos da SARM teriam se derivado. Apesar da reconhecida mobilidade do $\mathrm{Rb}$ e $\mathrm{Sr}$ em condições metamórficas, as elevadas razões ${ }^{87} \mathrm{Sr} /{ }^{86} \mathrm{Sr}_{(2,78 \mathrm{Ga})}$ obtidas para alguns dos metamafitos (i. e. 0,71618 a 0,71039 - Tabela 1) parecem admitir a possibilidade da contaminação em nível

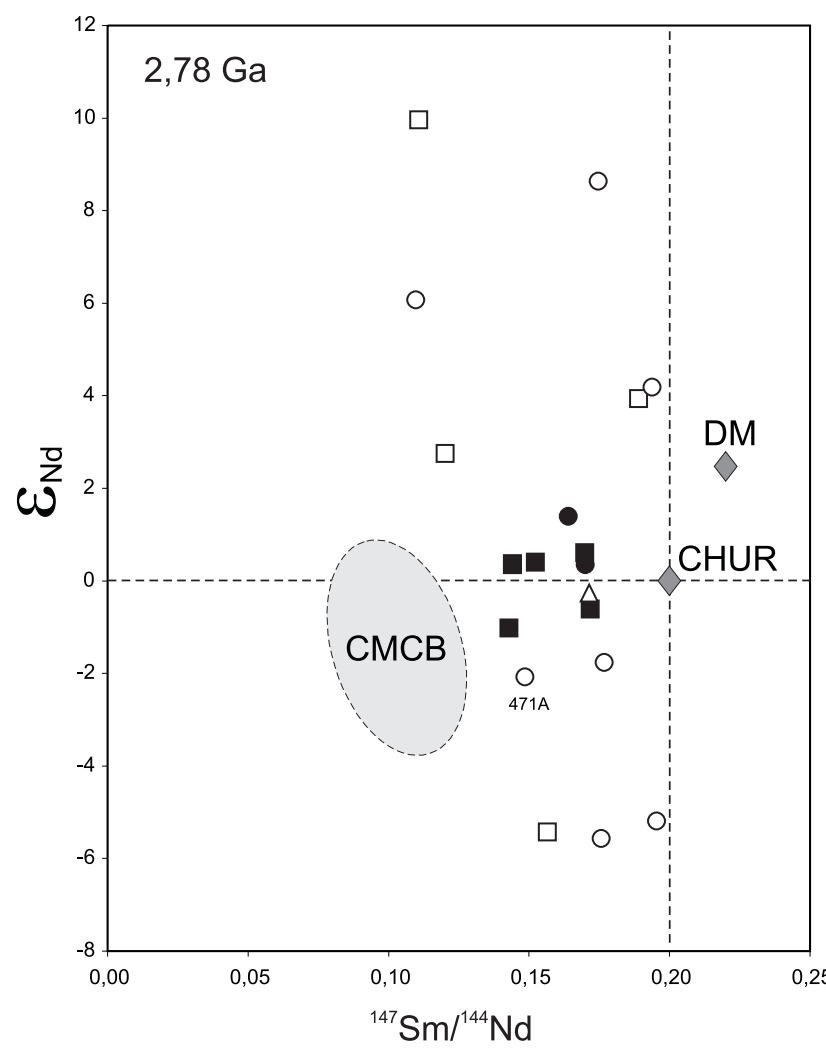

Figura 7. Diagrama de correlação isotópica $\varepsilon_{\mathrm{Nd}(2,78 \mathrm{Ga})} v{ }^{147} \mathrm{Sm} /{ }^{144} \mathrm{Nd}$ para as rochas da SARM. Símbolos cheios representam as amostras com sistemas isotópicos preservados. crustal raso, possivelmente a partir de fluidos associados à evolução da zona de cisalhamento Cláudio. A heterogeneidade isotópica do conjunto de amostras está ilustrada no diagrama $\mathcal{E}_{\mathrm{Nd}} v s^{87} \mathrm{Sr} /{ }^{86} \mathrm{Sr}_{(2,78 \mathrm{Ga})}$ (Figura 8), em especial no tocante às razões de $\mathrm{Sr}$, que são distintas em relação ao parâmetro-referência CHUR modelado para t =2,78 Ga.

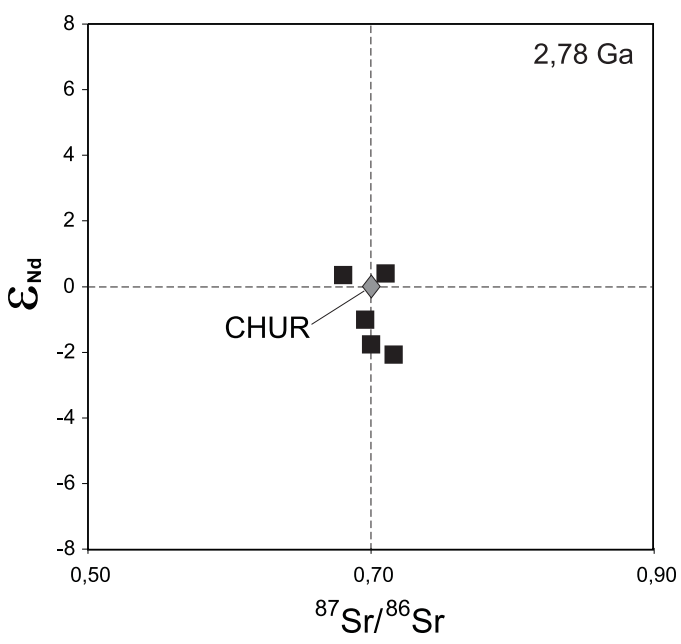

Figura 8. Diagrama $\varepsilon_{\mathrm{Nd}} v{ }^{87} \mathrm{Sr} /{ }^{86} \mathrm{Sr}_{(2,78 \mathrm{Ga})}$ para amostras da SARM (cf. Tabela 1), comparativamente ao parâmetro do manto CHUR.

\section{CONCLUSÕES}

Devido às peculiaridades geológicas do corpo estudado (e. g. uma seqüência acamadada, com predominância de intercalações de piroxenito e peridotito, texturas e estruturas magmáticas parcialmente preservadas e o caráter heterogêneo do metamorfismo e deformação) é provável que rochas da SARM sejam provenientes de um mesmo pulso magmático mantélico que foi cristalizado em condições crustais profundas, correlacionáveis à facies anfibolito superior. Essas condições poderiam explicar a trama granoblástica e a paragênese metamórfica de alto grau. Posteriormente, os magmatitos da SARM foram submetidos a condições metamórficas de facies xisto verde. A idade do processo metamórfico de alto grau não deve ser muito diferente da idade de cristalização magmática $\mathrm{Sm}-\mathrm{Nd}$ das rochas da SARM $(2,79 \pm 0,30 \mathrm{Ga})$, obtida a partir das sete amostras mais preservadas isotopicamente que, também, evidenciaram uma derivação mantélica a partir de uma fonte 
variavelmente enriquecida em termos de elementos incompatíveis, terras raras e isótopos de $\mathrm{Nd}$ e Sr. Assim considerado, esse processo metamórfico estaria geneticamente associado ao Evento Tectonotermal Rio das Velhas, pois a assinatura de manto fertilizado é sugestiva da presença de processos de subducção - hipótese coerente com a evolução neoarqueana desse evento (Machado e Carneiro, 1992) - às margens do fragmento continental mesoarqueano do CSFM ( $c f$. idades $\mathrm{T}_{\mathrm{DM}}$ da SARM e rochas da infra-estrutura - ver seção anterior). Os dados $\mathrm{Sm}-\mathrm{Nd}$ e $\mathrm{Rb}-\mathrm{Sr}$ restantes denotam a ocorrência de fracionamento e/ou distúrbio isotópicos. Acredita-se que esse comportamento seja decorrente de um dos seguintes processos ou da combinação desses, conforme sugerido pelas características petrográficas das amostras e dados de campo:

a. o metamorfismo de grau mais elevado teria mobilizado heterogeneamente o conteúdo dos elementos incompatíveis de parte das rochas estudadas e, conseqüentemente, afetado o sistema isotópico $\mathrm{Sm} / \mathrm{Nd}$ original;

b. as modificações isotópicas podem ter ocorrido durante o processo metamórfico de facies anfibolito superior, superimposto às rochas recém-cristalizadas da SARM;

c. os sistemas isotópicos podem ter sido afetados pela evolução tectônica da Zona de Cisalhamento Cláudio (Oliveira, 1999; Oliveira e Carneiro, 2001), já que a SARM situase no contexto desse lineamento crustal do CSFM (Figuras 1 e 2). Essa estrutura poderia, inclusive, ter contribuído com fluidos adicionais para os processos metamórficos superimpostos aos metamagmatitos da SARM, especialmente no caso do processo metamórfico de baixo grau, que teria mobilizado, em maior escala, os sistemas isotópicos estudados.

\section{AGRADECIMENTOS}

Esse trabalho foi possível graças ao apoio financeiro da FAPEMIG (Processos CRA 2697/98; CRA 225/02) e CNPq e ao suporte analítico dos seguintes laboratórios: LOPAG/ DEGEO/UFOP, CPGeo/IGc/USP e Laboratório de Geocronologia da UnB. Sinceros agradecimentos às essas instituições e às pessoas nelas envolvidas. Agradecemos a colaboração dos pesquisadores K. Sato e V. T. Martins na discussão dos dados analíticos, bem como as sugestões críticas dos revisores ad hoc.

\section{REFERÊNCIAS BIBLIOGRÁFICAS}

AVILA, C. A. Geologia, Petrografia e Geocronologia de corpos plutônicos paleoproterozóicos da borda meridional do Cráton do São Francisco, região de São João del Rei, Minas Gerais. 381 f. Tese (Doutorado) Instituto de Geociências, Universidade Federal do Rio de Janeiro, Rio de Janeiro, 2000.

BARBOSA, M. I. M.; PIRES, F. R. M.; NILSON, A. A. Geologia do Complexo Ultramáfico Acamadado Morro das Almas, região de Bom Sucesso e Ibituruna, MG. In: CONGRESSOBRASILEIRODE GEOLOGIA, 39., 1996, Salvador. Anais... Salvador: SBG, 1996. v. 2, p. 208-211.

BEN OTHMAN, D.; POLVÉ, M.; ALLÈGRE, C. J. Nd-Sr isotopic composition of granulites and constrains on the evolution of the lower continental crust. Nature, v. 307, p. 510-515, 1984.

BARBOSA, O. Resumo da Geologia do Estado de Minas Gerais. Boletim do Departamento de Serviços Geográfico e Geológico, v. 3, p.1-40, 1954.

BENNETT, V. S.; DePAOLO, D. J. Proterozoic crustal History of the Western United States as determined by neodymium isotopic mapping. Geological Society America Bulletin, v. 99, p. 674-685, 1987.

BUCHER, K.; FREY, M. Petrogenesis of metamorphic rocks complete revision of Winkler's textbook. 6 ed. Berlin: Springer-Verlag, 1994.318p.

BURTON, K. W.; O'NIONS, R. K. The timing of mineral growth across regional metamorphic sequence. Nature, v. 357, p. 235-238, 1992.

CAMPOS, J. C. S.; CARNEIRO, M. A.; BASEI, M. A. S. U$\mathrm{Pb}$ evidence for Late Neoarchean crustal reworking in southern São Francisco Craton (Minas Gerais, Brazil). Anais da Academia Brasileira de Ciências, v. 75, p. 497-511, 2003.

CARNEIRO, M. A.; TEIXEIRA, W.; NALINI JÚNIOR, H. A.; BILAL, E.; OLIVEIRA, A. H.; CARVALHO JÚNIOR, I. M. Archean ultramafic-mafic magmatism in the Southern São Francisco Craton (Campo Belo Complex): preliminary petrographic and geochemical results. In: SYMPOSIUM ON ARCHAEAN TERRANES OF THE SOUTH AMERICAN PLATAFORM, 1996, Brasília. Extended Abstracts... Brasília: SBG, 1996. p. 32-33.

CARNEIRO, M. A.; TEIXEIRA, W.; NOCE, C. M.; FERNANDES, R. A. Archaean growth processes in the Quadrilátero Ferrífero: a geochronological U-Pb and SmNd approach to the Rio das Velhas Event (2780 - 2700 MA). In: SYMPOSIUM ON ARCHAEAN TERRANES OF THE SOUTH AMERICAN PLATAFORM, 1., 1996, Brasília. Anais... Brasília: SBG, 1996. p. 59-60.

CARNEIRO M. A.; NALINI JÚNIOR, H. A.; BILAL, E.; CARVALHO JÚNIOR, I. M.; TEIXEIRA, W.; MOUTTE, J. A sequiência acamadada de Ribeirão dos Motas, Minas Gerais, Brasil. In: SEMANA DE GEOQUÍMICA, 10.; CONGRESSO DE GEOQUÍMICADOS PAÍSES DE LÍNGUA PORTUGUESA, 4., 1997, Braga. Actas... Braga: Universidade do Minho, 1997. p. 31-33.

CARNEIRO, M.A.; TEIXEIRA, W.; CARVALHO JÚNIOR, I. M.; OLIVEIRA, A. H.; FERNANDES, R. A. Archean 
$\mathrm{Sm} / \mathrm{Nd}$ isochron age from the Ribeirão dos Motas layered rocks sequence, Southern São Francisco Craton, Brazil. In: SOUTH-AMERICAN SYMPOSIUM ON ISOTOPE GEOLOGY, 1997, Campos do Jordão. Extended Abstracts... Campos do Jordão: FAPESP/CNPq/CPRM, 1997.p. 63-64.

CARNEIRO, M. A.; CARVALHO JÚNIOR, I. M.; FERNANDES, R. A.; TEIXEIRA, W. Geologia de parte do segmento crustal situado entre as cidades de Oliveira, Campo Belo e Santana do Jacaré, MG. In: SIMPÓSIO DE GEOLOGIA DE MINAS GERAIS, 9., 1997, Ouro Preto. Anais... Ouro Preto: SBG-Núcleo de Minas Gerais, 1997.p. 37.

CARNEIRO, M. A.; CARVALHO JÚNIOR, I. M.; TEIXEIRA, W. Petrologia, Geoquímica e Geocronologia dos diques máficos do Complexo Metamórfico Bonfim Setentrional (Quadrilátero Ferrífero) e suas implicações na evolução crustal do craton do São Francisco Meridional. Revista Brasileira de Geociências, v. 28, p. 29-44, 1998.

CARNEIRO, M.A.; TEIXEIRA, W.; CARVALHO JÚNIOR, I. M.; FERNANDES, R. A. Ensialic tectonic setting of the Archaean Rio das Velhas greenstone belt: $\mathrm{Nd}$ and $\mathrm{Pb}$ isotopic evidence from the Bonfim Metamorphic Complex, Quadrilátero Ferrífero, Brazil. Revista Brasileirade Geociências, v. 28, p.189-200, 1998.

CARVALHO JÚNIOR, I. M. Petrologia e geoquímica de rochas máficas e ultramáficas arqueanas do Cráton São Francisco Meridional: a seqüência acamadada Ribeirão dos Motas. 2001. 96 f. Dissertação (Mestrado) - Departamento de Geologia da Escola de Minas, Universidade Federal de Ouro Preto, Minas Gerais, 2001.

CARVALHO JÚNIOR, I. M.; CARNEIRO, M. A. Modelo petrogenético para os anfibólios ígneos intercumulus da sequiência acamadada de Ribeirão dos Motas. Pesquisa e Pós-graduação, v. 1, p. 26-32, 1999.

CARVALHO JÚNIOR, I. M.; CARNEIRO, M. A.; SUÍTA, M. T. F; TEIXEIRA, W. Anfibólio intercumulus na sequiência acamadada de Ribeirão dos Motas: um modelo petrogenético para sua origem. In: SIMPÓSIO DE GEOLOGIA DE MINAS GERAIS, 9., 1997, Ouro Preto. Anais... Ouro Preto: SBG-Núcleo de Minas Gerais, 1997. p. 38-39.

CARVALHO JÚNIOR, I. M.; CARNEIRO, M. A.; NALINI JÚNIOR, H. A.; TEIXEIRA, W. Seriam as rochas da seqüência acamadada de Ribeirão dos Motas o correspondente plutônico do magmatismo ultramáfico do Greenstone Belt Rio das Velhas? In: CONGRESSO BRASILEIRO DE GEOLOGIA, 40., 1998, Belo Horizonte. Resumos... Belo Horizonte: SBG-Núcleo de Minas Gerais, 1998.p. 68.

CARVALHO JÚNIOR, I. M.; CARNEIRO, M. A.; FERNANDES, R.A.; NALINIJÚNIOR, H.A.; TEIXEIRA, W. Processos mantélicos relacionados à gênese da estratificação ígnea da seqüência acamadada de Ribeirão dos Motas. In: CONGRESSO BRASILEIRO DEGEOLOGIA, 40., 1998, Belo Horizonte. Resumos... Belo Horizonte: SBG-Núcleo de Minas Gerais, 1998. p. 67.

CHAVES, A. O. Enxames de diques máficos do setor sul do Cráton do São Francisco - MG. 2001. 121 f. Tese (Doutorado) - Instituto de Geociências, Universidade de São Paulo, São Paulo, 2001.

CORREAA DA COSTA, P. C. Episódios de formação de crosta continental arqueana no Cráton São Francisco Meridional: um exemplo a partir da Região de Candeias Campo Belo, MG. 1999. 132 f. Dissertação (Mestrado) Departamento de Geologia da Escola de Minas, Universidade Federal de Ouro Preto, Ouro Preto, 1999.

DePAOLO, D. J. Neodymium isotope geochemistry. Berlin: Springer-Verlag, 1988. 187p.

DePAOLO, D. J.; LINN, A. M.; SCHUBBERT, G. The Continental age distribution: methods of determining mantle separation ages from $\mathrm{Sm}-\mathrm{Nd}$ isotopic data and application to the Southwestern United States. Journal of Geophysical Research, v. 96, 1991, p. 2071-2088.

EVANS, B. W.; FROST, B. R. Chrome-spinel in progressive metamorphism - a preliminary analysis. Geochemica et Cosmochemica Acta, v. 39, p. 959-972, 1975.

EVANS, B. W. Metamorphism of alpine peridotite and serpentinite. Annual Review of Earth and Planetary Sciences, v. 5, p. 397-447, 1977.

FAURE, G. Principles of isotope geology. New York: John Wiley e Sons, 1986. 589p.

FERNANDES, R. A. Etapas de formação de crosta continental (do Mesoarqueano ao Mesoproterozóico) no Cráton São Francisco Meridional. 2001. 127 f. Dissertação (Mestrado) - Departamento de Geologia da Escola de Minas, Universidade Federal de Ouro Preto, Ouro Preto, 2001.

GIOIA, S. M. C. I.; PIMENTEL, M. M. The Sm-Nd isotopic method in the Geochronology Laboratory of the University of Brasília. Anais da Academia Brasileira de Ciências, v. 72, p. 219-245, 2000.

MACHADO, N.; CARNEIRO, M. A. U-Pb evidence of late Archean tectono-thermal activity in the Southern São Francisco shield, Brazil. Canadian Journal of Earth Sciences, v. 29, p. 2341-2346, 1992.

MACHADO, N.; SCHRANK, A.; NOCE, C. M.; GAUTHIER, G. Ages of detrital zircon from Archean-Paleoproterozoic sequences: implications for Greenstone Belt setting and evolution of a Transamazonian foreland basin in Quadrilatero Ferrifero, Southeast Brazil. Earth and Planetary Science Letters, v. 141, p. 259-276, 1996.

OLIVEIRA, A. H. Evolução tectônica de um segmento crustal arqueano do Cráton São Francisco Meridional. 1999. 104 f. Dissertação (Mestrado) - Departamento 
de Geologia da Escola de Minas, Universidade Federal de Ouro Preto, Ouro Preto, 1999.

OLIVEIRA, A. H. Evolução tectônica de um fragmento do Cráton São Francisco Meridional com base em aspectos estruturais, geoquímicos (rocha total) e geocronológicos (Rb-Sr, Sm-Nd, Ar-Ar, U-Pb). 2004. $132 \mathrm{f}$. Tese (Doutorado) - Departamento de Geologia da Escola de Minas, Universidade Federal de Ouro Preto, Ouro Preto, 2004.

OLIVEIRA, A. H.; CARNEIRO, M. A. Campo Metamorphic Complex: tectonic evolution of an Archean sialic crust of the Northern São Francisco Cráton in Minas Gerais (Brazil). Anais da Academia Brasileira de Ciências, v. 73, p. 397-415, 2001.

PAKTUNÇ, A. D. Metamorphism of the ultramafic rocks of the Thompson Mine, Thompson Nickel Belt, Northern Manitoba. Canadian Mineralogist, v. 22, p. 77-91, 1984.

PINESE, J. P. P. Geoquímica, geologia isotópica e aspectos petrológicos dos diques máficos pré-cambrianos da Região de Lavras (MG), porção sul do Cráton do São Francisco. 1997, 178 f. Tese (Doutorado) - Instituto de Geociências, Universidade de São Paulo, São Paulo, 1997.

PROJETO Radambrasil. Folhas sf.23/24 Rio de Janeiro/ Vitória: geologia, geomorfologia, pedologia, vegetação, uso potencial da terra. RIO DE JANEIRO: DNPM, 1983. p. 39-45. (Levantamento de Recursos Naturais, 32.)

SATO, K.;TASSINARI, C. C. G.; KAWASHITA, K.; PETRONILHO, L. O método geocronológico Sm-Nd no IG/USP e suas aplicações. Anais da Academia Brasileira de Ciências, v. 67, p. 315-336, 1995.

SCHNEIDER, M. E.; EGGLER, D. H. Fluids in equilibrium with peridotite. Geochimica et Cosmochimica Acta, v. 50, p. 711-724, 1986.

SCHORSCHER H. D. Evolução geotectônica e petrogenética do embasamento arqueano do Quadrilátero Ferrífero. Anais da Academia Brasileira de Ciências, v. 51, p. 766-768, 1979.

TASSINARI, C. C. G.; MUNHÁ, J. M. U.; TEIXEIRA, W.; PALÁCIOS, T.; NUTMAN, A. P.; CESAR SOSA, S.; SANTOS, A. P.; CALADO, B. O. The Imataca Complex, NW Amazonian Craton, Venezuela: crustal evolution and integration of geochronological and petrological cooling histories. Episodes, 2004. No prelo.

TAYLOR, S. R.; MCLENNAN, S. M. The Continental Crust: its composition and evolution. Boston: Blackwell Scientific, $1985.312 \mathrm{p}$.

TEIXEIRA, W.; CARNEIRO, M. A.; NOCE, C. M.; MACHADO, N.; SATO K.; TAYLOR P. N. Pb, Sr and Nd isotope constraints on the Archean evolution of gneissicgranitoid complexes in the Southern Sao Francisco Craton. Precambrian Research, v. 78, p. 151-164, 1996.

TEIXEIRA, W.; CORDANI, U. G.; NUTMAN, A. P.; SATO,
K. Polyphase Archean evolution in the Campo Belo Metamorphic Complex, Southern Sao Francisco Craton, Brazil: SHRIMP U-Pb evidence. Journal of South American Earth Sciences, v. 11, p. 279-290, 1998.

TEIXEIRA, W.; SABATÉ, P.; BARBOSA, J.; NOCE, C. M.; CARNEIRO, M. A. Archean and Paleoproterozoic tectonic evolution of the São Francisco Craton. In: CORDANI, U. G.; MILANI, E. J.; THOMAZ FILHO, A.; CAMPOS, D. A. (Ed.). Tectonic evolution of South America. Rio de Janeiro: 31. International Geological Congress, 2000. p. 101-137.

VALENÇA, J. G.; PACIULO, F. V. P.; RIBEIRO, A. E.; ANDREIS, R. R. Komatítos da Fazenda Chapadinha, Faixa Greenstone Itumirim-Tiradentes, Borda Sul do Cráton São Francisco, Minas Gerais, In: CONGRESSO BRASILEIRODE GEOLOGIA, 40., Belo Horizonte, 1998. Resumos... Belo Horizonte: SBG/Núcleo de Minas Gerais, 1998. p. 62.

WAGER, L. R.; BROWN, G. M. Layered igneous rocks. London: Oliver e Boyd, 1967. 588p. 